\title{
DE VICENTE A FLORESTAN: UMA BREVE ANÁLISE DE UMA TRAJETÓRIA ESCOLAR DE SUCESSO
}

\author{
FROM VICENTE TO FLORESTAN: A BRIEF ANALYSIS OF A SUCCESSFUL SCHOOL
}

\section{Patricia Silva}

Universidade Federal do Rio de Janeiro, Rio de Janeiro, RJ, Brasil. E-mail: patthyp@gmail.com

DOI: https://doi.org/10.46550/amormundi.v1i2.24

Recebido em: 21.09.2020

Aceito em: 10.11.2020

Resumo: o presente artigo dedica-se a apresentar e a analisar, ainda que de forma breve, a trajetória do sociólogo brasileiro Florestan Fernandes. Essa análise está focada nos itinerários escolares e educacionais do sociólogo. O presente trabalho foi desenvolvido com os preceitos da pesquisa bibliográfica, analisando-se entrevistas, artigos e obras sobre o autor. A análise apoiou-se, ainda, no arcabouço teórico-epistemológico produzido por pesquisadores e estudiosos da Sociologia da Educaçáo. Estima-se que este trabalho possa contribuir para aqueles que se dedicam a estudar trajetórias escolares bem-sucedidas, especialmente aquelas de indivíduos pertencentes às camadas populares.

Palavras-chave: trajetórias, sucesso escolar, camadas populares

Abstract: this article is dedicated to presenting and analyzing, albeit briefly, the trajectory of the Brazilian sociologist Florestan Fernandes. This analysis is focused on the sociologist's school and educational itineraries. The present work was developed with the principles of bibliographic research, analyzing interviews, articles and works about the author. The analysis was also based on the theoretical-epistemological framework produced by researchers and scholars from the Sociology of Education. It is estimated that this work can contribute to those who are dedicated to studying successful school trajectories, especially those of individuals belonging to the popular strata.

Keywords: trajectories, scholar success, popular strata

\section{Consideraçóes iniciais}

Quando eu nasci, veio um anjo safado, um chato de um Querubim, que decretou que eu estava predestinado a ser errado assim, já de saída minha estrada entortou, mas vou até o fim. Quando garoto, deixei de ir a escola, cassaram meu boletim... (Chico Buarque)

presente artigo tem o objetivo de apresentar uma breve análise da biografia do
renomado sociólogo Florestan Fernandes. O sociólogo, indivíduo oriundo das camadas sociais populares, é um exemplo de sucesso escolar; o pensador possui uma história de vida ímpar e "quase impensável à luz do padrão de sociabilidade das nossas elites intelectuais" (PONTES, 2003, p.147) 
Segundo Viana (1998), as práticas e as intervenções realizadas pelas famílias de camadas médias, endógenas ao processo escolar, não ocorrem nas camadas populares. Se o fracasso escolar é a tônica das trajetórias dos filhos das famílias de camadas populares, compreender o sucesso escolar daqueles que escapam dessa tônica torna-se necessário. As famílias de camadas populares tendem a apresentar expectativas de escolarização de seus filhos articuladas à melhoria das suas condiçóes de trabalho; essas famílias esperam que seus filhos consigam um emprego melhor que o de seus pais, como mostra Maria Alice Nogueira (1991).

O artigo utilizou a pesquisa bibliográfica como metodologia de pesquisa e está assentado no arcabouço teórico produzido pela Sociologia da Educação, com especial atenção aos estudos que se dedicam à análise de trajetórias educacionais e/ou escolares de indivíduos provenientes das camadas populares. Dados da biografia de Florestan foram obtidos através de páginas da internet (conforme indicado nas notas de rodapé ao longo do texto) e livros.

Para fins didáticos, o presente texto foi organizado, estruturalmente, de acordo com as etapas da vida do sociólogo que, segundo a análise livre da autora, marcaram passagens importantes de sua biografia, especialmente no que concerne à sua trajetória educacional e vida escolar. A estrutura do texto é a seguinte: a) a infância no bairro humilde do Brás; b) retorno aos estudos; d) a morte de Vicente.

Estima-se que o texto possa contribuir com o debate sobre o sucesso escolar nos meios populares ao promover reflexão sobre a trajetória de um dos maiores sociólogos que o Brasil já teve.

\section{A infância no bairro humilde do Brás}

Florestan Fernandes nasceu em São Paulo, no dia 22 de julho de 1920, numa família humilde do Brás, bairro periférico de São Paulo, de um parto que envolveu risco de vida por subnutrição de sua mãe, Dona Maria Fernandes, uma portuguesa lavadeira e analfabeta. Ela, quando grávida de Florestan, conseguiu um emprego na casa de um casal sem filhos de classe média alta de São Paulo - a família Bresser.

Dona Maria Fernandes, ao começar a trabalhar na casa dos Bresser, encontrou apoio na amizade de um motorista alemáo chamado Florestan, um homem gentil e generoso, que se casaria posteriormente com sua melhor amiga. Por esta grande amizade, Dona Maria decidiu batizar seu filho com o nome Florestan ${ }^{1}$.

À época do batismo, a patroa de sua mãe, que viria a ser a madrinha de Florestan, não admitia que o bebê se chamasse Florestan. Passou, então, a chamá-lo de Vicente, pois julgava que Florestan não era nome apropriado para uma criança pobre. Ainda bem cedo, Florestan precisou ajudar sua mãe na manutenção de ambos:

Digamos que no início eu repartia com minha mãe a obrigação de sustentar o lar. Ela tinha dois filhos: eu e uma menina, que morreu com 5 anos. Costumo dizer que nós vivíamos ao léu, pois podíamos estar na Bela Vista, no Bosque da Saúde, na Penha ou no Brás. Nós morávamos em pequenos cortiços ou em poróes e quando o aluguel subia éramos obrigados a abandonar o lugar em que

1 O nome é uma exaltação a um personagem da única ópera de Bethoven, Fidélio, drama sevilhano no qual a mulher Leonora luta pelo seu amor, Florestan, e consegue libertá-lo das masmorras de Dom Pizzarro. A ópera, concluída em 1814, quando a Áustria esteve sob domínio de Napoleão, é mais do que uma exaltação ao amor; é um hino à liberdade e à justiça. 
estávamos. Nós éramos tocados pela vida, de uma maneira dura. Minha mãe trabalhou como doméstica e depois como lavadeira. Mais tarde, quando tinha 14 anos, me tornei arrimo. A nossa vida era difícil. Depois de algum tempo, fui morar com um amigo da enteada de minha madrinha: a dona da casa chamavase dona Vilma de Castro. O marido dela, José de Castro Manso Preto. Quando souberam que eu só comia sanduíches e tomava leite, ou então ia comer em restaurante de comida chinesa, que naquela época era a mais barata que havia em São Paulo, me chamaram para jantar e exigiram que comesse na casa deles. Eles moravam na avenida Celso Garcia, no antigo número 141. Para mim era fácil, porque ali pegava o bonde para o Bom Retiro. Eu descia numa rua que dava direto na alameda Nothmann e dali seguia para o Ginásio Riachuelo, onde em três anos fiz o equivalente a sete anos de estudos. Nessa época, fui vender artigos dentários. Passei, então, a ter liberdade para freqüentar o curso de ciências sociais da Faculdade de Filosofia, na praça da República. (FERNANDES,1991 apud VENCESLAU,2006, s/p) ${ }^{2}$

A colaboração do filho para poder arcar com as despesas do lar foi um fator que precocemente ensinou muito a Florestan: “ (...) sofri muitas privaçôes na infância. Tive de começar a trabalhar com 6 anos e ficava afastado de casa de oito até dez horas por dia.” (FERNANDES,1991 apud VENCESLAU,2006, s/p).

Florestan começou a trabalhar com apenas seis anos de idade, como ele mesmo conta:

Com 6 anos, eu só podia fazer pequenas tarefas, como, por exemplo, limpar as costas de fregueses em barbearias para ganhar gorjetas. Uma vez uma senhora me pediu para transportar uma caixa de mangas da Estaçáo da Luz até a rua Treze de Maio. Imagine se há humanidade ou sentido cristão nesse tipo de trabalho! Ganhei quatrocentos réis para fazer isso. Eu fazia todo tipo de coisa até descobrir que ser engraxate era uma coisa boa para mim. Trabalhei em açougue, marcenaria, alfaiataria, padaria, restaurante, bar, até que fui trabalhar na Novoterápica. Nesse ínterim consegui acabar o curso de madureza — não havia terminado o primário. O curso primário eu fiz um pouco em uma escola privada na avenida Celso Garcia, perto da casa da minha madrinha. Depois minha mãe me tirou de lá e fui para o Grupo Escolar Maria José, onde estudei até o $3^{\circ}$ ano. (FERNANDES, 1991 apud VENCESLAU,2006, s/p)

No currículo profissional de Florestan, constam trabalhos como engraxate, auxiliar de marceneiro, auxiliar de barbeiro, balconista de bar, carpinteiro e alfaiate. Foi a partir destas e de outras experiências que ele conseguiu penetrar no mundo e sentir nas relaçóes entre os adultos a voracidade do homem como lobo do próprio homem³.

Apesar das dificuldades enfrentadas, Florestan encontrava alento e inspiração: "eu não estava sozinho. Havia minha mãe. Porém, a soma de duas fraquezas não compóe uma força. Éramos varridos pela 'tempestade da vida' e o que nos salvou foi nosso orgulho selvagem..." (FERNANDES, 1977, p.142)

Ao relembrar a sua condição de "típico morador pobre da cidade de São Paulo na década de 20", Florestan afirma que

O menino que eu era vivia [...] fascinado pelo luxo de uns ou pela pompa dos que desciam de carros com motoristas de libré, abrindo as portas, diante do Teatro

2 O trecho foi extraído de uma entrevista disponível em: VENCESLAU, Paulo de Tarso. Florestan Fernandes. Entrevista publicada em 26/09/2006. Disponível em www.iff.org.br. (Acesso em janeiro de 2008)

3 "O homem é o lobo do homem" é uma máxima atribuída ao filósofo Thomas Hobbes quando este dissertava sobre a natureza egoísta do homem. 
Municipal ou do Cine Paramount; passando o dia-a-dia oscilando entre a fome e a fartura, trabalhando como se fosse adulto - o código de honra de ninguém evitava esse "fardo de criança" - e tendo de admitir que a limpeza exigente de minha mãe não excluía a presença das baratas, a roupa remendada e larga - ganha de famílias generosas ou herdada dos mais velhos. (FERNANDES,1977 apud PONTES,2003, p.146-147)

$\mathrm{Na}$ casa da família Bresser, Florestan viveu até os três anos de idade. Após este período, muda-se para diversos locais na cidade de Sáo Paulo. Anos depois, quando Florestan já tinha seis anos, voltou a morar na casa de sua madrinha. Enquanto morou ali, estudou numa escola primária particular do Brás.

Florestan apontava que o convívio com a família Bresser despertou nele a percepção das diferenças sociais, do padrão de vida que ele e sua mãe levavam em relação aos outros e o quanto era importante a instrução. Sua mãe e sua madrinha eram duas referências muito próximas de Florestan que, ao mesmo tempo, mostravam a ele duas condiçóes sociais radicalmente diferentes.

Em seu processo de escolarização, não foram poucas as dificuldades econômicas que encontrou. Florestan freqüentou o Grupo Escolar Maria José, cujo diretor ficara seu amigo. Diz ele: "Lá fui munido com o mínimo de requisitos da vida na cidade, pois aprendi a ler, escrever e contar; e a escola não foi tão sofrível, já que adquiri os rudimentos para me tornar um autodidata exemplar". (FERNANDES, 1977, p. 146)

Como sua vida no trabalho estava exigindo que se dedicasse em período integral, aos nove anos de idade, Florestan intemporreu os estudos no terceiro ano do curso primário. Se hoje as estatísticas de evasão escolar são alarmantes, no início do século XX, a situação era ainda pior; a educação brasileira tinha fortes marcas de marginalidade (SAVIANI,1999)

\section{Retorno aos estudos}

Ainda que a necessidade temporária de intemporrer os estudos tenha acometido sua vida, Florestan aponta que nunca parou de estudar, mesmo que informalmente e de forma precarizada:"eu nunca parei de estudar. A minha mãe teve um companheiro que se chamava João de Carvalho, que tinha vários livros. E eu, na casa da minha madrinha, aprendi a valorizar a cultura. Juntando essas duas coisas à minha curiosidade, acabei me tornando um autodidata." (FERNANDES, 1991 apud VENCESLAU,2006, s/p)

Aos dezessete anos, Florestan ingressou no antigo curso de madureza ${ }^{4}$ por insistência dos fregueses do Bar Bidu, na Rua Líbero Badaró, onde trabalhava como cozinheiro. Os fregueses achavam que Florestan era muito inteligente devido aos seus comentários sobre história e política, além de apresentar uma leitura crítica da realidade.Sobre a época que trabalhou no Bar Bidu, Florestan conta:

[Trabalhei] na copa e na cozinha do bar Bidu. Fazia um sanduíche com aliche e salsa picada (eu tenho habilidade para lidar com a faca) que o Manuel Lopes Teixeira, da Novaterápica, adorava. Eu colocava um pozinho verde e azeite português e fazia um pacotinho para ele levar. Um dia, o Maneco ficou esperando que o bar fechasse, saiu comigo e me perguntou o que pretendia fazer na vida. Respondi que gostaria de estudar. "E por que você não sai desse emprego e estuda?" Eu disse: "Já tentei mas não consegui." Naquela época, as pessoas mais estigmatizadas

4 Curso de educação de jovens e adultos. 
socialmente eram as prostitutas, os negros e as pessoas que trabalhavam em bares e restaurantes. Ninguém dava outro emprego para nós. Aí ele falou: "Você vai poder estudar, porque vou arrumar um outro emprego para você. Mas você precisa fazer o tiro-de-guerra, senão vai ter de interromper os estudos. E também precisa aprender datilografia. Quando estiver tudo pronto, você me avisa." Eu tive uma conversa com os donos do bar, que eram muito meus amigos. Para eles era ruim que eu saísse três vezes por semana na hora de pico do movimento. Mas como eu era considerado um funcionário exemplar, eles cederam. Aí eu ia ao tirode-guerra 546, que funcionava na rua do Carmo; e fiz o curso de datilografia na praça da Sé. Quando terminei, avisei o Maneco e ele me colocou na Novoterápica como entregador de amostras. Depois, passei a cuidar do estoque e mais tarde fui promovido a chefe da seçấo de dentes. Era capaz de separar dentes por cor e por tipo. Daí a facilidade com que me transferi para a área de artigos dentários do Boticão Universal. Quando fiz os exames e entrei para a faculdade, passei a vender artigos recebendo ajuda de custo e comissão. Passado algum tempo, o Maneco descobriu que a Pio Miranda e Cia. ia precisar de um propagandista. Fiz um concurso e consegui o cargo. O pessoal do laboratório acreditava que eu gastava oito horas por dia para fazer oito visitas. Mas, na verdade, eu gastava muito menos. Era o posto ideal para eu poder estudar. Sobrava tempo para ir à escola e estudar à noite. Com isso, consegui me formar. Eu me casei em 1944 e, como o salário de professor-assistente não era suficiente para nos mantermos, ainda trabalhei por dois anos como propagandista. Os médicos, meus clientes, ficavam constrangidos, porque achavam que eu, professor-assistente, era hierarquicamente superior a eles. (FERNANDES, 1991 apud VENCESLAU,2006, s/p)

Ao lado do bar, havia um sobrado no qual instalou-se o Ginásio Riachuelo. Através da intervenção de um professor, Florestan teve a oportunidade de dar continuidade aos estudos com pagamento reduzido. Depois de prestar serviço militar e aprender datilografia ${ }^{5}$, com o auxílio de um dos fregueses, Manuel Lopes Teixeira (conhecido como Maneco), Florestan conseguiu um outro emprego, na Novoterápica, com o qual foi possível custear seus estudos e manter a si e sua mãe. Ele relata que lá teve seus primeiros flertes com o socialismo:

$\mathrm{Na}$ Novoterápica conheci o Scalla, auxiliar do Maneco. A família dele era vinculada ao socialismo. E havia um italiano, que depois se casou com uma irmã dele, recém-chegada da Itália com idéias muito frescas sobre o movimento socialista europeu. Eu tinha lido muitos livros, mas sem sistematização. O contato com essa família serviu para tornar as coisas mais claras para mim. E comecei a freqüentar as redaçóes de O Estado de São Paulo e, principalmente da Folha da Manhã, onde conheci o Hermínio Sacchetta, que era líder do movimento trotskista, ligado à IV Internacional. Assim, em 1943, me tornei militante do Partido Socialista Revolucionário (...). (FERNANDES, 1991 apud VENCESLAU, 2006, s/p)

No Ginásio, Florestan logo se mostrou determinado. Considerando que ele e alguns colegas trabalhavam durante o dia, o diretor da escola deu a chave do prédio onde funcionava o Ginásio para que ali tivessem espaço para estudar após as aulas. Em decorrência disto, aos poucos se formou um pequeno grupo de estudos, como ele mesmo lembra:

Passei, então, do pato ao ganso. As minhas leituras desordenadas adquiriram outra direção e, pela primeira vez, passei a ler os clássicos com afinco e a me concentrar sobre a literatura, especialmente a brasileira (...) O Riachuelo converteu-se em um segundo lar, ou melhor, em um 'lar coletivo'. Tomamos conta do prédio nos sábados pela tarde e durante todo o dia nos domingos (...) Se náo era uma

5 Ver mais em: http://www.fgv.br/cpdoc/acervo/dicionarios/verbete-biografico/fernandes-florestan (acesso em janeiro de 2021) 
comunidade-escola, tínhamos uma escola-comunidade e, sob o seu impulso, a minha imaginação se abriu para além do imediato, do cotidiano e para os 'grandes problemas' da literatura, da filosofia e da época; autores de segunda ordem, mas conhecidos, entraram em nossas cogitações (...) Hoje um analista exigente sentiria pena do jovem que é condenado, pela sociedade em que vive, a percorrer caminhos tão tortuosos e íngremes para chegar à 'Ilustraçáo'. Para nós aquilo era puro mel e uma revolução. (FERNANDES, 1977, p.149)

Florestan foi ampliando seu horizonte cultural, o que, segundo ele, fez com que pensasse em realizar um curso superior para se qualificar como professor. Inicialmente, ele pensava em ser engenheiro químico, mas os horários eram incompatíveis com seu trabalho. Conta ele:

Eu queria fazer engenharia química. Não pude porque não tinha recursos para me manter na escola o dia inteiro. Por isso, tive de escolher entre os cursos de meio período. Destes, o que me atraiu mais foi o de ciências sociais. Foi uma boa escolha, porque a minha ambição era ser professor. Quando acabei o curso, tive dois convites para ser assistente na Faculdade de Filosofia. (FERNANDES apud VENCESLAU,2006, s/p.)

Após concluir o curso de madureza no Riachuelo, Florestan se candidatou à seleção para o curso de Ciências Sociais e Políticas da Faculdade de Filosofia, Ciências e Letras (FFCL) da Universidade de São Paulo (USP). Florestan comenta que "os candidatos às Ciências Sociais, por exemplo, faziam um exame escrito e um exame oral de sociologia. $\mathrm{Na}$ argüição oral, diante dos dois Bastides e de outro professor do qual não me lembro, coube-me discutir um trecho de De la Division du Travail Social'. (FERNANDES, 1977, p.155). Os dois Bastides a quem Florestan faz menção são os professores Roger Bastide e Paul Arbousse Bastide.

Nos exames para o curso de Ciências Sociais, havia trinta vagas disponíveis; vinte e nove pessoas se inscreveram e apenas seis desses foram classificados. Florestan ficou em quinto lugar, como ele conta: "Com o madureza, eliminei todo o atraso e fui o quinto colocado entre os estudantes aprovados no exame para a faculdade”(FERNANDES, 1991 apudVENCESLAU,2006).

Sua opção pelas Ciências Sociais, motivada por um ainda embrionário conhecimento sobre socialismo e pelo desejo então impreciso de mudar a sociedade, passou ao largo da escolha de uma profissão em si. Ele que, até então se sustentara com empregos variados, ingressou na graduação sem se colocar esse problema. Isso pode ser explicado pelo fato que, no começo da década de 1940, ninguém sabia com clareza o que era ser cientista social e muito menos o que se poderia esperar dessa profissão.

\section{A morte de Vicente}

Atuando, então, como vendedor de produtos farmacêuticos, Florestan, em 1941, ingressa na graduação em Ciências Sociais. Neste momento, ele dizia que o Vicente começou a morrer e sobreveio o Florestan ${ }^{6}$.

As aulas no curso de Ciências Sociais eram densas. Soma-se a isto o fato dos professores serem estrangeiros, o que obrigou os alunos a aprenderem o francês, o italiano e o inglês para, assim, poderem acompanhar às aulas:

Quando fui para a Faculdade de Filosofia, a escolha de ciências sociais estava

6 Ver mais em: https://fpabramo.org.br/publicacoes/wp-content/uploads/sites/5/2020/01/Cartilha3-Realidade-Brasileira. pdf (A biografia de Florestan Fernandes encontra-se entre as páginas 20 e 28 - acesso em janeiro de 2021) 
nebulosamente imbricada à idéia de que eu teria um conhecimento que seria útil para transformar a sociedade. Depois vi que, ao contrário, a estrutura do curso estava voltada para estudar a sociedade de uma maneira científica, não havia polarização ideológica. $\mathrm{Na}$ faculdade, a maioria dos professores era composta por franceses, um deles era alemão, poucos eram brasileiros. (FERNANDES, 1991 apud VENCESLAU,2006)

Florestan concluiu o bacharelado em 1943, ano em que o jornal O Estado de São Paulo publicou o seu primeiro artigo. No ano seguinte, ele conclui a licenciatura. ${ }^{7}$

Em 1944, Florestan tornou-se assistente do professor Fernando de Azevedo, na cátedra de Sociologia II. Obteve, então, o mestrado pela Escola de Sociologia e Política de São Paulo em 1947 com a dissertação "A organização social dos tupinambá". Concluiu o doutorado pela FFCL-USP em 1951, com a tese "A função social da guerra na sociedade tupinambâ", sob a orientação do professor Fernando de Azevedo. Nos trabalhos produzidos para a pós-graduação, Florestan constrói, por meio de documentos de viajantes, a estrutura da tribo dos Tupinambá, já desaparecida na época. No mesmo ano, Florestan casou-se com Myriam Rodrigues Fernandes, com quem teve seis filhos. Sobre o casamento, Florestan conta: "eu conheci a Míriam na casa de um amigo meu que namorava sua irmá. Ele se chamava Coríntio Palma e trabalhava na Novoterápica. O namoro foi longo, uns cinco, seis anos. Depois me casei." (FERNANDES, 1991 apud VENCESLAU,2006, s/p).

Após a conclusão do doutorado, Florestan tornou-se livre-docente da USP na cátedra de Sociologia I, e posteriormente, tornou-se catedrático (equivalente a professor titular atualmente, mas numa estrutura em que a hierarquia era muito mais rígida).

Defensor da educação pública, Florestan sempre foi ligado aos movimentos sociais e reivindicatórios e às organizaçôes políticas de esquerda ${ }^{8}$. Em 1964, foi preso político do presídio do Exército em São Paulo. Ao ser libertado, tornou-se professor catedrático na USP, sendo efetivado em 1965 por meio de concurso de títulos e provas. Foi novamente preso no mesmo ano e solto em 1966.

Afastado de suas atividades na USP através do Ato Institucional no 5 da Ditadura Militar (1969), ficou exilado no Canadá entre 1969 e 1970, onde assumiu um lugar como professor de Sociologia na Universidade de Toronto.

Florestan retornou ao Brasil em 1972, passando a atuar como professor de cursos de extensão cultural no Instituto Sedes Sapientiae em São Paulo. Foi também professor visitante da Universidade de Yale em 1977, até ser contratado como professor da Pontifícia Universidade Católica de São Paulo (PUC - SP) no final deste mesmo ano, onde tornou-se professor titular em 1978.

Florestan, a convite de Luis Inácio Lula da Silva, inicia sua vida partidária no Partido dos Trabalhadores, mas mantém-se, como ele mesmo se intitulava, "lobo solitário", sendo admirado e respeitado por todas as alas do PT.

Florestan faleceu em São Paulo no dia 10 de agosto de 1995, aos 75 anos de idade, vítima de embolia gasosa maciça (presença de bolhas de ar no sangue), seis dias após submeter-se a um transplante de fígado.

7 Ver mais em: http:/www.fgv.br/cpdoc/acervo/dicionarios/verbete-biografico/fernandes-florestan (Acesso em: janeiro de 2006)

8 Ver mais em: http://www.interpretesdobrasil.org/sitePage/63.av (Acesso em: janeiro de 2006). 


\section{Consideraçóes finais}

A seletividade a que é submetida à clientela da escola no Brasil é expressa nas altas taxas de fracasso escolar entre alunos dos meios populares. Apesar de transferir as razóes da seletividade e, consequentemente do fracasso, a certos bodes expiatórios (incapacidade do professor, incapacidade do alunado, falta de verbas para educaçáo etc.), não podemos deixar de situá-los, em primeiro lugar, em termos dos determinantes socioeconômicos que, em certa instância, são os responsáveis pelo fato de uns, mais que outros, conseguirem sobreviver e serem bem-sucedidos no sistema de ensino. As classes populares caracterizam-se pelo pequeno volume de seu patrimônio, qualquer que seja o tipo de capital considerado, como o capital cultural e o capital econômico (NOGUEIRA, 2004).

Florestan Fernandes, de engraxate a professor catedrático, é um exemplo de trajetória de sucesso entre alunos oriundos dos meios populares. Sua trajetória se aproxima do tipo de aluno denominado por Bourdieu (1998, p.46) como "superselecionado", pois compensou a desvantagem inicial que devem à atmosfera cultural de seu meio e não teve uma trajetória escolar planejada: era o homem certo para a faculdade de destino ainda incerto.

É importante notar que a família transmite aos seus filhos, certo capital cultural ou ethos. Segundo Bourdieu, a herança cultural pode ser diferenciada sob dois aspectos: a classe social que "é responsável pela diferença inicial das crianças diante da experiência escolar e,consequentemente, pelas toscas de êxito” (BOURDIEU, 1998, p. 42).

Não há nenhuma passagem da biografia de Florestan Fernandes, disponibilizada ao conhecimento público, que sugira o apoio direto da mãe na sua escolarização e tão pouco o provimento de um ambiente familiar que favorecesse a socialização e a escolarização. Mas é conveniente ressaltar que a ausência do apoio da mãe não sugere que a mesma tenha proibido Florestan de estudar. Como observa Lahire (1997), o investimento pedagógico não é a única condição capaz de interferir nos resultados escolares. Embora a mãe não acompanhe diretamente os conteúdos escolares, adota outras formas de investimento, seja no plano mais subjetivo, como a insistência constante em transmitir o valor social da educação, seja de ordem disciplinar, não autorizando a interrupção dos estudos, controlando a assiduidade e o cumprimento das tarefas de casa.

A origem social de Florestan, somada às dificuldades de toda ordem que enfrentara na infância e na adolescência, dificilmente lhe franquearia o ingresso em um curso como o de Direito ou o de Medicina. $\mathrm{Na}$ ausência de qualquer tipo de capital (cultural, econômico ou social), Florestan encontrou na graduação em Ciências Sociais o espaço possível para romper com o círculo de ferro de sua condição social.

A escolarização foi a principal estratégia de mobilidade social ascendente de Florestan Fernandes. Bourdieu (1987), a partir de uma análise da sociedade do ponto de vista macrossocial, denomina os casos de mobilidade social via escola como milagrosos.

É possível, diante disto, compreender que Florestan trilhou uma trajetória escolar de sucesso por motivação pessoal e, mais posteriormente, por incentivo de amigos e colegas de trabalho; sua trajetória se deu de acordo com as disposiçóes temporais, com a inexistência de projetos de escolarizaçáo de longo prazo. Cada passo dado o conduzia para horizontes novos. Cada obstáculo da vida do sociólogo era superado com êxito. Analisando sua própria trajetória escolar, Florestan faz a seguinte ponderação: 
Sentia-me à vontade com os colegas e era um estudante promissor para alguns professores (...) $\mathrm{O}$ importante para mim, é que essa aceitação criava as perspectivas para realizar uma vocação intelectual insuspeitada. $\mathrm{O}$ caminho estava aberto para me tornar um professor e para chegar até onde o meu talento e a minha capacidade de trabalho pudessem levar-me. (FERNANDES, 1977, p.162)

A formação escolar do sociólogo foi potencializada, sobretudo, pela reflexão que o mesmo fazia sobre seu meio social de origem: "eu nunca teria sido o sociólogo em que me converti sem o meu passado e sem a socialização pré e extra escolar que recebi através das duras liçóes da vida”. (FERNANDES, 1977, p.142).

Florestan dedicou-se durante toda sua vida à luta contra a desigualdade social. Intelectual orgânico, no sentido empregado por Gramsci, foi militante na defesa da escola pública de qualidade e com forte influência marxista, acreditou, lutou e defendeu a transformação social, atribuindo papel relevante aos trabalhadores a partir da consciência de classe e incluindo a educação como tema de grande destaque na construção e consolidação de um novo projeto de sociedade.

Referências

BOURDIEU, Pierre. A Doxa e a vida cotidiana:uma entrevista. In:ZIZEK, Slavoj (org). Um mapa da Ideologia.Rio de Janeiro: Contraponto,1996.p.265-278.

BOURDIEU, Pierre. A economia das trocas simbólicas. São Paulo: Perspectiva, 1987.

BOURDIEU, Pierre. A escola conservadora: as desigualdades frente à escola e à cultura. In: NOGUEIRA, Maria Alice \& CATANI, Afrânio (orgs). Escritos de Educaçáo. Petrópolis, Vozes, 1998, p-39-64.

LAHIRE, Bernard. Sucesso escolar nos meios populares: as razóes do improvável. São Paulo: Atica, 1997.

NOGUEIRA, Maria Alice. Bourdieu e a educação. Belo Horizonte: Autentica, 2004.

FERNANDES, Florestan. A sociologia no Brasil. Petrópolis: Vozes, 1977.

PONTES, Heloísa André. Resenha do livro "Destino ímpar: sobre a formação de Florestan Fernandes", de Syvia Garcia. Mana - Estudos de Antropologia Social, Rio de Janeiro, v. 9, n. 1, p. 146-148, 2003. Disponível no site www.scielo.com.br (Acesso em janeiro/2008)

SANTOS, Robinson. Florestan: a formação pela práxis. Revista Espaço Acadêmico número 52. Setembro/2005. Disponível no site http://www.espacoacademico.com.br/052/52ff_santos. htm (Acesso em janeiro/2008)

SAVIANI, Demerval. Escola e Democracia. Campinas: Autores Associados, 1999.

VENCESLAU, Paulo de Tarso. Florestan Fernandes. Entrevista publicada em 26/09/2006. Disponível em www.iff.org.br. (Acesso em janeiro de 2008).

VIANA, Maria José. Longevidade escolar em famílias de camadas populares: algumas condiçôes de possibilidade. Belo Horizonte: FAE-UFMG, 1998 [ Tese de doutorado]. 